\title{
Cell Biology and Ethics: Knowledge, Attitudes and Practices of Anatomists in India
}

\author{
Mangala Kohli1 ${ }^{*}$, Reeha Mahajan1, Payal Bansal'2, Anita Tuli1, P. A. Athira1 \\ ${ }^{1}$ Department of Anatomy, Lady Hardinge Medical College, \& Associated Hospitals, New Delhi, India \\ ${ }^{2}$ Institute of Medical Education \& Technology \& Teacher's Training, Maharashtra University of Health Sciences, \\ Pune, India \\ Email: ${ }^{*}$ mangalakohli1@gmail.com
}

Received December 2014

\begin{abstract}
Most scientific discoveries and advancements have occurred in the world in the last century. Both developed and developing countries are the beneficiaries of the new scientific knowledge and its application. Advanced knowledge and the ethical issues are inseparable from research, treatment, prophylaxis and prevention involving human diseases. It is necessary to make well informed decisions about acceptance of advancements that have taken place elsewhere and also prepare systems for our research and medical education. Bioethics therefore needs to be grounded in the local socio cultural context and health care systems. Students make first contact with human biological tissue in the Anatomy department. The seeds of ethical practices and professionalism are sown here. Therefore appropriate knowledge and attitudes of anatomists and cell biologists towards human tissue is important for regular practice of medicine. A questionnaire based study of knowledge and attitudes of $\mathbf{3 0 0}$ anatomy faculty related to use of human biological materials in research and education was conducted. The items included in the questionnaire were to judge the awareness about the same i.e., laboratory handling of human material and research related to corpses, organ \& whole body donation along with their use in clinical learning and research in various medical specialties like, orthopedics, surgery, ENT, anesthesia etc. for clinicians, physicians and surgeons as well as undergraduate, post graduate and allied workforce teaching. The data collected from the respondents in the form of positive and negative responses was analyzed. The study identifies the knowledge gaps and the perceptions of faculty regarding the scope and utility of understanding the role of human biological tissues in curriculum and research and transmission of message to the next generation of learners.
\end{abstract}

\section{Keywords}

Human Biological Material, Bioethics, Undergraduates, Anatomists, Professionalism

\footnotetext{
${ }^{*}$ Corresponding author.
}

How to cite this paper: Kohli, M., Mahajan, R., Bansal, P., Tuli, A. and Athira, P.A. (2015) Cell Biology and Ethics: Knowledge, Attitudes and Practices of Anatomists in India. Journal of Biosciences and Medicines, 3, 66-72. 


\section{Introduction}

Anatomy has been a cornerstone of medical education for hundreds of years. Many argue that it has survived the most demanding pedagogic test time. Anatomy deals with the structure of the human body, and it is the human body and human tissues that are central to bioethical questions concerning life in both health and disease, in research and clinical practice. Anatomy, as a discipline has a number of ethical dimensions. Bioethics is the study of the typically controversial ethical issues emerging from new situations and possibilities brought about by advances in biology and medicine. Human material with potential for use in biomedical research related to anatomy includes cadaver as a whole, organs and parts of organs, cells and tissue, embryos and fetal Tissue. India is a multicultural community. It is important that the practices of body, organ and tissue donation take into account the cultural, ethical, spiritual and religious views of all those concerned. This need to respect different viewpoints gives added importance to ensuring that each person makes a wise decision on donation.

Ethics is that part of philosophy which concerns good behaviour. Ethics searches common fundamentals for morality. It applies certain philosophical approaches to human life and behaviour. Ethics is challenged by problems related to cultural, legal, religious and market regulations. The practice of bioethics is related to survival as an effective social institution [1].

Ethical issues related to practices in the subject of anatomy can be categorized into following headings:

\subsection{Role of Institutional Ethics Committee (IEC)/Institutional Review Board (IRB)}

The use of human tissue for medical and scientific research is a sensitive issue. Researchers should assure themselves that any proposal involving human tissue is ethically acceptable.

\subsection{Informed Consent}

Informed consent means an agreement, compliance or permission given voluntarily without any compulsion [2]. It can be defined as "the voluntary and revocable agreement of a competent individual to participate in a therapeutic or research procedure, based on an adequate understanding of its nature, purpose and implications" [3]. Waiver of the consent requirement may be applied in certain circumstances where no foreseeable harm is expected to result from the study or when permitted by law, federal regulations, or if an ethical review committee has approved the non-disclosure of certain information [4].

\subsection{Unjustified Mutilation of the Cadaver}

The dissection of the human body represents an important part of medical education. The knowledge of anatomy thus acquired contributes decisively to the specialized training of physicians in general and of the future surgeons in particular [5] [6]. An unjustified mutilation of the cadaver during dissection or a manipulation that infringes the accepted moral standards is ethically blamable or even judiciary punishable. Medical practitioners should not participate in mutilating procedures at the request of persons who wish to photograph or video the results in furtherance of commercial or "artistic" aims [7].

\subsection{Ethical Issues Related to Use of Formalin}

According to ICMR guidelines, good working conditions have to be ensured by the ethical committee at the place of research. Formalin has an irritant effect on the eyes, mucosa, has tendency to cause allergic reactions and carcinogenicity. So, protection of the medical students and researchers working on cadaveric and fetal material has to be taken care of as it is an occupational hazard.

\subsection{Confidentiality}

If the material is to be used for research purposes anonymity is readily assured. Protected health information (PHI) of decedents is also covered under the HIPAA (Health Insurance Portability and Accountability Act) for cadaveric organ, eye or tissue donations and for research purposes [8].

\subsection{Perinatal/Fetal Autopsy}

The perinatal necropsy is an important investigation following fetal or neonatal loss [9]. Fetal autopsy comes 
under the domain of department of anatomy in many institutions. All autopsies should follow stringent rules of ICMR which are based on the Helsinki declaration [10]. The perinatal necropsy appears to have been relatively immune to the considerable fall in necropsy rates affecting adult hospital patients over the last 40 years, attributable to, among other many and complex factors, consent for necropsy [11]-[13]. The Australia Law Reform Commission describes a necropsy merely as a postmortem examination of the body of the deceased for the purposes of scientific interest in determining the cause of death and other information that may be obtained that might aid medical science [14]. The Polkinghorne report recommends that specific informed consent be sought from parents for such use of tissue [15]. Perinatal autopsy is the gold standard for detecting clinically missed diagnosis but legal and ethical problems need to be sorted out to increase perinatal autopsy rate [16].

The anatomists need to be well acquainted with all the ethical and legal aspects concerning human biological material. The current knowledge and awareness of the anatomists needs to be judged for assessing the requirement of its introduction into the medical curriculum. The present study is the first of its kind, highlighting the importance of assessing the knowledge, attitude and practices of Anatomists regarding bioethics in the Indian context.

\section{Materials and Methods}

A questionnaire based study on the knowledge, attitudes and practices (KAP) related to the use of human biological materials in research and education was conducted on 300 anatomists which included faculty members and senior as well as junior residents. The respondents included anatomists selected on the basis of convenience sampling from Medical colleges in Delhi-NCR, Uttar Pradesh, Maharashtra, Punjab and Jammu \& Kashmir. A twenty-eight item self-administered structured and validated questionnaire about knowledge, beliefs and attitudes towards principles and practice of bioethics in the subject of anatomy, informed consent and role of an ethics committee in a tertiary care teaching hospital was prepared. The items included in the questionnaire were to judge the awareness about the same i.e., laboratory handling of human material and research related to corpses, organ \& whole body donation along with their use in clinical learning and research in various medical specialities like, orthopaedics, surgery, ENT, anaesthesia etc. for clinicians, physicians and surgeons as well as undergraduate, post graduate and allied workforce teaching. The items included both open-ended and closed ended questions which were categorized into four sets. The first set of questions evaluated the knowledge of the anatomists about the presence of an ethics committee (IEC) in the institution, its composition, role and finally their satisfaction about the role of the ethics committee. They were also inquired whether all studies involving human beings need to be reviewed by IEC and what type of studies are exempted. The second set of questions assessed the awareness of the respondents about the codes, regulations and guidelines like Nuremberg code, the Helsinki declaration, revised guidelines of ICMR for biomedical research on human participants and the source of their knowledge. The third set of questions judged the KAP of anatomists about procurement, preservation and handling of human cadaveric and foetal material. The fourth set of questions analyzed the ethical issues encountered by anatomists in research, publication, setting up a fetal repository, conducting cadaveric workshops and the impact of introduction of bioethics in the medical curriculum. Both the open and closed-ended questions were scrutinized separately. The data collected from the respondents was analyzed, tabulated and the results were summarized by subjecting to calculation of percentages.

\section{Results}

We contacted 300 subjects (anatomists) and circulated the questionnaire either personally or via personal E-mail. Out of total 300, only 236 subjects returned the filled questionnaire. Thus, the response rate was $78.7 \%$.

\section{Responses to $1^{\text {st }}$ set of questions:}

About 99.58\% respondents were aware of the Ethical committee in their respective institutes. $96.61 \%$ subjects knew that non-medicos like, legal expert, ethicist, layperson are part of ethical committee and $93.64 \%$ faced ethical problem in research work. The major ethical problems faced were in relation to obtaining informed consent \& research involving foetal tissue. 97.88\% thought that ethical committee clearance is required for all research work while only $0.85 \%$ negated the view thinking that studies on biomedical wastes are exempted from it. Majority of the participants responded that the role of ethical committee is to supervise and monitor every step of research and it safeguards the welfare and the rights of participants and gives approval to research. 86.02\% subjects could enumerate the composition and role of ethical committee satisfactorily. Surprisingly, only $28 \%$ 
anatomists participating in the study knew about the chairman of the ethical committee of their institution. $90 \%$ respondents believed that research work cannot be pursued after rejection of application by ethical committee (Figure 1).

\section{Responses to $2^{\text {nd }}$ set of questions:}

Majority of the respondents were aware of the Nuremberg code, Revised ICMR guidelines on bioethics and Helsinki declaration. The respondents obtained knowledge on bioethics from various sources. 58\% subjects considered ICMR guidelines, 30\% believed in experience and previous research, $4 \%$ relied on internet and 1\% considered workshops as their source of knowledge on bioethics (Figure 2).

\section{Responses to $3^{\text {rd }}$ set of questions:}

Interestingly, majority of the respondents were of the view that necessary precautions are taken and participants are aware of bioethical issues associated with cadaveric handling during workshop. According to 95\% respondents, cadavers are procured in the medical schools both by body donation and unclaimed bodies (Figure 3).

About $84 \%$ of anatomists knew about the other chemicals used for embalming in addition to formalin. Formalin is used as a preservative by $14 \%$ of participants in their respective institutions while $84 \%$ subjects used other chemicals like alcohol, glycerine and thymol in addition to formalin. Majority of the respondents (91\%) held incineration as the mode of disposal of remains of cadavers and prosected specimens (Figure 4).

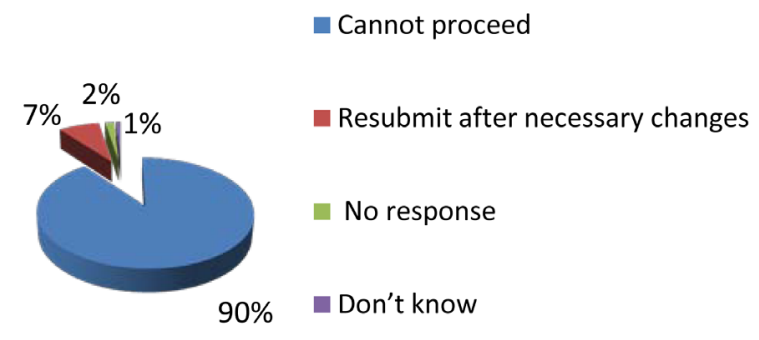

Figure 1. Responses to the question "How do you pursue your research work even after rejection of application by the ethical committee?”.

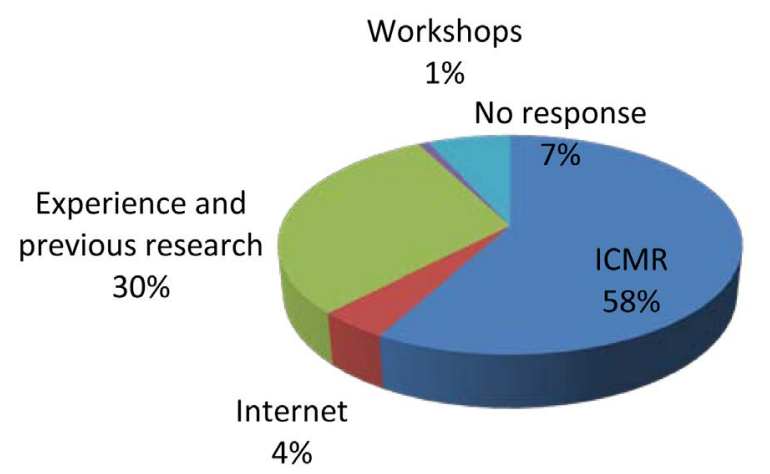

Figure 2. Source of knowledge on bioethics.

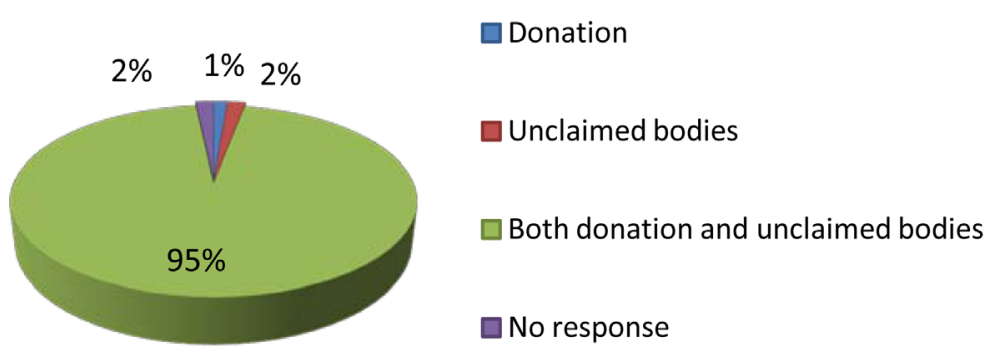

Figure 3. Method of procuring cadavers. 




Figure 4. Method of disposal of cadavers and prosected specimens.

$10 \%$ formalin is used by the institutions with a fetal repository to preserve foetuses. To the question, what is the attitude expected from medical students for the use \& disposal of cadaveric tissue, 96.61\% responded. The respondents expect the students to respect the cadaver $\&$ that the tissue be disposed as per the colour coding in yellow bags.

\section{Responses to $4^{\text {th }}$ set of questions:}

93\% respondents had fetal repository in their institute. All the institutes with a foetal repository in the anatomy department, obtain written informed consent from the parents in the language they understand. $97.03 \%$ responded to the question on the importance of bioethics in relation to cell biology. $88.14 \%$ could give a satisfactory response to the question on importance of bioethics in relation to cell biology. Respondents feel that the bioethics will help to educate \& create awareness amongst medical professionals. It will also educate the medical professionals about the legal aspects involved in the research work. 99.58\% believed that teaching of bioethics to first year MBBS students can have an impact on their professional behavior. All the respondents felt the need of introducing educational activities in the field of bioethics in the medical curriculum.

\section{Discussion}

Anatomy and ethics have traditionally been viewed as inhabiting different conceptual worlds on the assumption that the practice of anatomy is ethically neutral. This assumption is challenged by critiquing the nature of anatomy and by demonstrating that ethical issues pervade anatomical study. The manner in which we respond to the dead, the use we make of their skeletal remains and tissues, and the ways in which we learn about ourselves by studying them, raise ethical queries that go to the heart of what it means to be human [17].

These ethical issues in relation to anatomy are discussed under following heads:

\section{Role of Institutional Ethics Committee:}

In the present study, $97.88 \%$ thought that ethical committee clearance is required for all research work in the subject of anatomy while only $0.85 \%$ negated the view thinking that studies on biomedical wastes are exempted from it which is in accordance with view that research requiring ethical review include research involving human remains, cadavers, biological fluids, tissues, embryos, fetuses etc. [18]. Ethics committee members include: Chair person, preferably from outside the institution, 1 - 2 basic medical scientists, 1 - 2 clinicians from various institutes, one legal expert or retired judge, one social scientist, one philosopher or ethicist, one lay person from community, member secretary [19] [20] and surprisingly 96.61\% subjects knew that non-medicos like, legal expert, ethicist, layperson are part of ethical committee. 86.02\% subjects could enumerate the composition and role of ethical committee satisfactorily which is dissimilar to results by another author [21] who demonstrated that $76.6 \%$ and $75.4 \%$ medical and dental postgraduates respectively knew about the role of ethical committee. Only 28\% anatomists participating in the present study knew about the chairman of the ethical committee of their institution while other researchers have observed better results where $50 \%$ faculty and $60 \%$ residents were aware of the chairman [22] Responsibility of Institutional Ethics Committee was to determine safety of proposed intervention in humans, scientific soundness of proposed research, ethical correctness of the research, good working conditions at the research site, to determine the informed consent requirement, to maintain records of decisions [19] [20]. It stresses the need for informed consent, with donors being given clear information upon which to base their decision, intentions to bequest being made by the donor before death and encourages donors to discuss their wishes to bequeath with relatives prior to death. In the current study, majority of the participants responded that the role of ethical committee is to supervise and monitor every step of research and it safeguards the welfare and the rights of participitants and gives approval to research. All the roles of the ethical committee were not known by the respondents. 


\section{Informed Consent and Confidentiality:}

The general principles issued by ICMR include principles of informed consent, non-exploitation, essentiality, privacy and confidentiality [19] [20] which is in concordance with the findings of the present study where written informed consent was obtained from the parents (93\% respondents) in all the institutions with a foetal repository. This suggests that Indian Anatomists are very much aware of the importance of informed consent as compared to other studies where $83.8 \%$ medical postgraduates[21] and $64.5 \%$ faculty [22]. Majority of the respondents were aware of the Nuremberg code, Revised ICMR guidelines on bioethics and Helsinki declaration in our study and the percentage is much higher than observations in medical faculty by other authors [21] [22].

\section{Unjustified Mutilation of the Cadaver:}

To ensure respectful treatment to the cadaver from students, the invaluableness of donated bodies and the feelings of the donors behind body donation should be stressed on mind. In the present study, the attitude expected from medical students for the use \& disposal of cadaveric tissue includes respect for the cadaver \& the disposal as per the colour coding in yellow bags avoiding undue mutilation which was concordant with the practice of honoring the cadaver at the commencement of medical course session and dissection by students and teachers followed in Korea [23] and Thialand [24].

The present study is a forerunner in assessing the knowledge of anatomists regarding the procurement and preservation of human biological material as observed by responses of $3^{\text {rd }}$ set of questions. To the best of our knowledge, no comparable studies have been done by any of the authors. This assessment is important as a legislation was passed by the UK government to limit the concentrations of formaldehyde in the dissection rooms and embalming suites as it was not without risk to personel [25]-[27].

$58 \%$ respondents in the present work obtained knowledge on bioethics from ICMR guidelines (Figure 3) which is in contradiction to findings of another investigator [21] who found internet and newspapers (50\% respondents) as the source of knowledge on bioethics. 99.58\% of participants believed that teaching of bioethics to first year MBBS students can have an impact on their professional behavior as students make first contact with human biological tissue in the Anatomy department and seeds of ethical practices and professionalism are sown here. All felt the need of introducing educational activities in the field of bioethics in the medical curriculum which is in accordance with studies by other authors [28]-[30].

\section{Conclusion}

Medical ethics teaching and training should help the student at any level whatever may be the discipline to assimilate and conceptualize the basic principles of ethical reasoning. Innovative strategies should be devised to work within the time constraints of the existing medical curriculum and importantly, to increase student interest and engagement. The new bioethics curriculum needs to be comprehensive and robust, and strives to develop medical professionals who, in addition to being technically skilled and competent, are well-versed in the history and philosophy of ethics and bioethics and are ethical in their thinking and practice, especially in the context of a developing country like India. The study identifies the knowledge gaps and the perceptions of anatomists regarding the scope and utility of understanding the role of human biological tissues in curriculum and research and transmission of message to the next generation of learners.

\section{References}

[1] Roy, D.J. and Lambert, R.D. (2000) L’éthique des sciences dela vie: À un carrefour? Médecine/Sciences, 16, 11921197. http://dx.doi.org/10.4267/10608/1552

[2] Pillay, V.V. (2003) Handbook of Forensic Medicine and Toxicology. 13th Edition, Paras Publication, Hyderabad, 2425.

[3] Sim, J. (1986) Informed Consent: Ethical Implications for Physiotherapy. Physiotherapy, 72, 584-587.

[4] Council for International Organization of Medical Sciences (CIOMS) and World Health Organization (WHO) Geneva, Switzerland (2002) International Ethical Guidelines for Biomedical Research Involving Human Subjects.

[5] Mimms, C. (2006) Death Enciclopedia. Editura Orizonturi, Bucureşti, 241-265.

[6] Varghese, S.P. (2005) Cadavers for Anatomical Dissection. Indian Journal of Medical Ethics, 13.

[7] Nuffield Council on Bioethics (1995) Human Tissue: Ethical and Legal Issues (London).

[8] Protecting Personal Health Information in Research: Understanding the HIPAA Privacy Rule. HTML-Posted April 14, 
2003. http://privacyruleandresearch.nih.gov/pr_02.asp

[9] Porter, H.J. and Keeling, J.W. (1987) Value of Perinatal Necropsy Examination. Journal of Clinical Pathology, 40, 180-184. http://dx.doi.org/10.1136/jcp.40.2.180

[10] Indian Council of Medical Research (2006) Ethical Guidelines for Biomedical Research on Human Participants [Internet]. ICMR, New Delhi. http://www.icmr.nic.in/ethical_guidelines.pdf

[11] Joint Working Party of the Royal College of Pathologists, Royal College of Physicians of London and Royal College of Surgeons of England (1991) The Autopsy and Audit. The Royal College of Pathologists, London.

[12] Smallwood, R. (1994) The Dead Do Tell Tales. Medical Joutrnial of Auistralia, 160, 389-390.

[13] Editorial [Anonymous] (1994) Research after Death. Lancet, 344, 1517-1518. http://dx.doi.org/10.1016/S0140-6736(94)90341-7

[14] The Royal College of Pathologists of Australasia (1994) Autopsy and the Use of Tissues Removed at Autopsy. Medical Journal of Australia, 160, 442-444.

[15] Polkinghorne, J., Hoffenberg, R., Kennedy, I. and Macintyre, S. (1987) Review of the Gutidanice on the Research Luse Offetluses Anid Fetal Miaterial. Her Majesty’s Stationerv Office, London, 7.

[16] Pradhan, R., Mondal, S., Adhya, S. and Raychaudhuri, G. (2013) Perinatal Autopsy: A Study from India. Journal of Indian Academy of Forensic Medicine, 35, 10-13.

[17] Jones, D.G. (1998) Anatomy and Ethics: An Exploration of Some Ethical Dimensions of Contemporary Anatomy. Clinical Anatomy, 11, 100-105. http://dx.doi.org/10.1002/(SICI)1098-2353(1998)11:2<100::AID-CA6>3.0.CO;2-Y

[18] Shah, N. (2005) Ethical Guidelines for Biomedical Research on Human Subjects. Trends in Biomaterials and Artificial Organs, 18, 174-177.

[19] Ethical Guidelines for Biomedical Research on Human Subjects (2000) Indian Council of Medical Research. New Delhi.

[20] International Ethical Guidelines for Biomedical Research Involving Human Subjects (2002) Council for International Organizations of Medical Sciences. Geneva.

[21] Janakiram, C. and Gardens, S.J. (2014) Knowledge, Attitudes and Practices Related to Healthcare Ethics among Medical and Dental Postgraduate Students in South India. Indian Journal of Medical Ethics, 11, 99-104.

[22] Mohammad, M., Ahmad, F., Rahman, S.Z., Gupta, V. and Salman, T. (2011) Knowledge, Attitudes and Practices of Bioethics among Doctors in a Tertiary Care Government Teaching Hospital in India. Journal of Clinical Research Bioethics, 2, 118. http://dx.doi.org/10.4172/2155-9627.1000118

[23] Park, J.T., Jang, Y., Park, M.S., Pae, C., Park, J., Hu, K.S., et al. (2011) The Trend of Body Donation for Education Based on Korean Social and Religious Culture. Anatomical Sciences Education, 4, 338. http://dx.doi.org/10.1002/ase.198

[24] Winkelmann, A. and Guldner, F.H. (2004) Cadavers as Teachers: The Dissecting Room Experience in Thailand. BMJ, 329, 1455-1457. http://dx.doi.org/10.1136/bmj.329.7480.1455

[25] Health and Safety Executives Guidance Notes on Formaldehyde Exposure Levels (UK Government) (1990) EH 40/90. Control of Substances Hazardous to Health Regulations.

[26] Pabst, R. (1987) Exposure to Formaldehde in Anatomy: An Occupational Health Hazard. Anatomical Record, 219, 109-112. http://dx.doi.org/10.1002/ar.1092190202

[27] Robbins, A. and Bingham, E. (1980) Formaldehyde: Evidence of Carcinogenicity. Joint NIOSH/OSHA, Current Intelligence Bulletin No 34. NIOSH Publications Dissemination (Division of Technical Services, Cincinati, US).

[28] Selvakumar, D. and Joseph, L.B. (2004) The Importance of including Bio-Medical Ethics in the Curriculum of Health Education Institutes. Education for Health (Abingdon), 17, 93-96. http://dx.doi.org/10.1080/13576280310001656204

[29] Ravindran, G., Kalam, T., Lewin, S. and Pais, P. (1997) Teaching Medical Ethics in a Medical College in India. National Medical Journal of India, 10, 288-289.

[30] Miyasaka, M., Akabayashi, A., Kai, I. and Ohi, G. (1999) An International Survey of Medical Ethics Curricula in Asia. Journal of Medical Ethics, 25, 514-521. http://dx.doi.org/10.1136/jme.25.6.514 